\title{
Erratum to: Tympanic Membrane Boundary Deformations Derived from Static Displacements Observed with Computerized Tomography in Human and Gerbil
}

\author{
Stefan L. R. Gea ${ }^{1}$, Willem F. Decraemer ${ }^{1}$, W. Robert J. Funnell ${ }^{2,3}$, Joris J. J. Dirckx ${ }^{1}$, \\ and Hannes Maier ${ }^{4}$ \\ ${ }^{1}$ Biomedical Physics, University of Antwerp, Groenenborgerlaan 171, 2020, Antwerp, Belgium \\ ${ }^{2}$ Department of BioMedical Engineering, McGill University, Montréal, Canada \\ ${ }^{3}$ Department of Otolaryngology, McGill University, Montréal, Canada \\ ${ }^{4}$ HNO Universitätsklinikum Hamburg-Eppendorf, Martinistr. 52, 20246, Hamburg, Germany
}

Online publication: 29 April 2010

Erratum to: JARO

DOI $10.1007 /$ s10162-009-0192-9

W. Robert J. Funnell was misidentified in the original publication of this article; his name is correct as displayed above. JARO regrets the error.

The online version of the original article can be found at http://dx.doi.org/10.1007/s10162-009-0192-9.

Correspondence to: Willem F. Decraemer - Biomedical Physics .

University of Antwerp - Groenenborgerlaan 171, 2020, Antwerp,

Belgium. Telephone: +32-3-2653430; fax: +32-3-2653318; email: wim.

decraemer@ua.ac.be 